\title{
Optimal Design of a PV-Wind system for water pumping
}

\author{
José L. Bernal-Agustín, Rodolfo Dufo-López, José A. Domínguez-Navarro, José M. Yusta-Loyo
}

Electrical Engineering Department. University of Zaragoza.

C/ María de Luna, 3. E-50018 Zaragoza, Spain.

\begin{abstract}
.
This paper shows the optimization of a PVWind system to supply the demand of water pumping in a small town in Bolivia. This work has been done with the HOGA program (Hybrid Optimization by Genetic Algorithms). The objective function to minimize in the design process is the total Net Present Cost (NPC) of the system. The system is defined as a combination of components (PV panels and wind turbines). In this case HOGA has used as an enumerative method of design, evaluating all the possible solutions to the design problem. In the example shown, the optimal system found is a Wind-Only system, not a hybrid system, due to the prices of the components and the metheorological conditions for this case.
\end{abstract}

Keywords: Hybrid PV-Wind Systems, Optimization.

\section{Introduction.}

Electric generation hybrid systems are usually more reliable and less costly which the systems than use a single source of energy [1].
The mathematical design problem (sizing and control of the hybrid system) involves a significant number of variables [2]. The optimization of this kind of problems can be successfully done by the enumerative methods (if the number of combinations of components and control strategies is low and the computation time is acceptable) or by genetic algorithms (if the number of combinations is high and the enumerative method implies high computation times). The optimization has been done by HOGA program (Hybrid Optimization by Genetic Algorithms), which was introduced in [3-7]. In this case, as there are only two components (PV panels and wind turbines) and there are no control strategies involved, the enumerative method is adequate.

In this paper the optimisation of a PV-Wind system, without batteries (see Fig. 1) to supply the electrical demand for water pumping in a small town located near La Paz (Bolivia) is described.

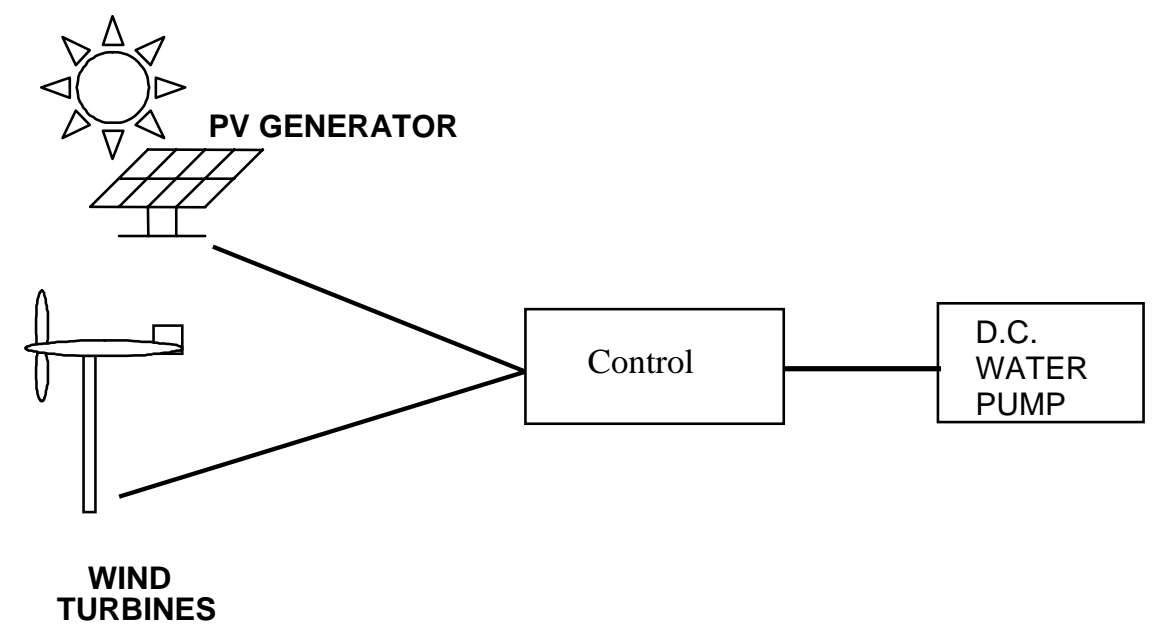

Figure 1. PV-Wind system for water pumping. 


\section{Water pumping.}

The town is located near La Paz (Bolivia), latitude $13^{\circ} 30^{\prime}$ 'South, longitude $68^{\circ} 8^{\prime}$ ' West. The altitude is 3,600 $\mathrm{m}$ over sea level.

The daily water consumption of the town is 30 $\mathrm{m}^{3} /$ day (we have considered that it is the same for all the days in the year), and the hourly water consumption profile through the day is shown in Fig. 2.

Water is pumped by a DC pump from the river to a water tank of $100 \mathrm{~m}^{3}$ capacity, and the town water consumption is supplied from this water tank.

Pumping elevation head + suction lift is $20 \mathrm{~m}$, friction losses are $10 \%$, pump electrical rated power is $1,000 \mathrm{~W}$, total pump efficiency is $40 \%$ and pump minimum power is $10 \%$.
The total annual energy demanded by the pumps to supply the annual water consumption is:

$$
\begin{aligned}
& E_{\text {pumping_annual }}=\frac{Q \cdot \rho \cdot g \cdot H \cdot\left[1+\frac{H_{\text {loss }}}{100}\right]}{\eta_{\text {pump }}}=\frac{30 \cdot 365 \mathrm{~m}^{3} \cdot 1000 \frac{\mathrm{kg}}{\mathrm{m}^{3}} \cdot 9.81 \frac{\mathrm{m}}{\mathrm{s}^{2}}}{0.4} \\
& =5.908 \cdot 10^{9} \mathrm{~J}=1641 \mathrm{kWh}
\end{aligned}
$$

We consider the water tank capacity at the beginning of the simulation $\left(0 \mathrm{~h}, 1^{\text {st }}\right.$ of Janyuary) is $30 \mathrm{~m}^{3}$.

The maximum unmet load allowed (maximum water non served) is $0.1 \%$ in the year.

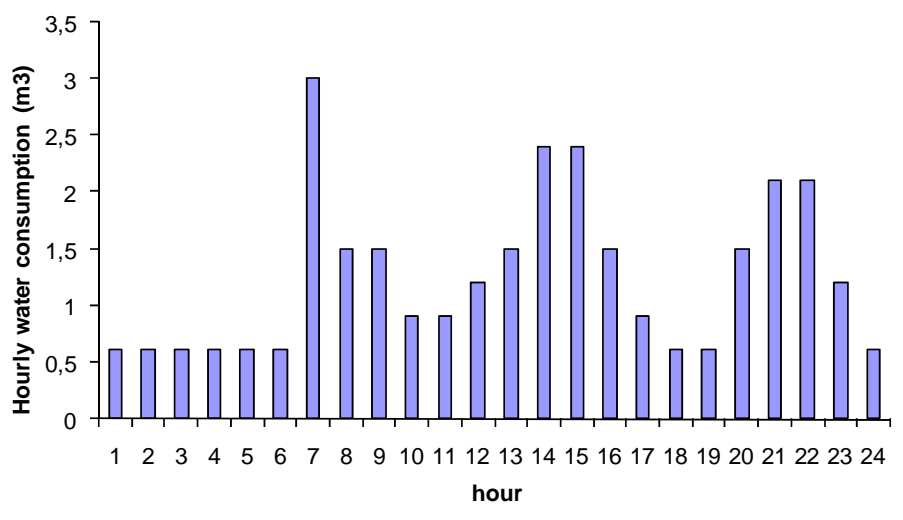

Figure 2. Hourly water consumption profile through the day.

\section{Resources.}

The wind speed hourly data and the irradiation in the area of the town have been obtained from the U.S. Department of Energy, Energy Efficiency and Renewable Energy, EnergyPlus Weather

File

(EPW) (http://www.eere.energy.gov/buildings/energypl us/cfm/weather_data.cfm)

The wind speed hourly data at a height of $10 \mathrm{~m}$ is shown in Fig. 3. and the hourly data of irradiation on horizontal surface is shown in Fig. 4.

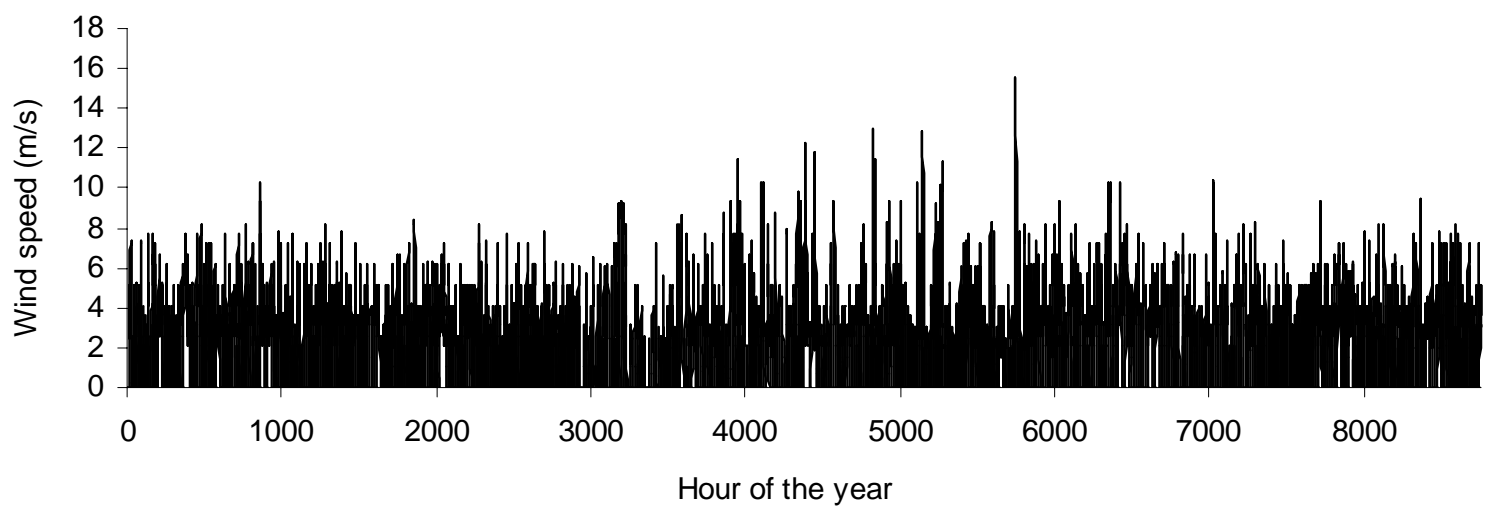

Fig. 3. Wind speed data $(\mathrm{m} / \mathrm{s})$ at a height of $10 \mathrm{~m}$. 


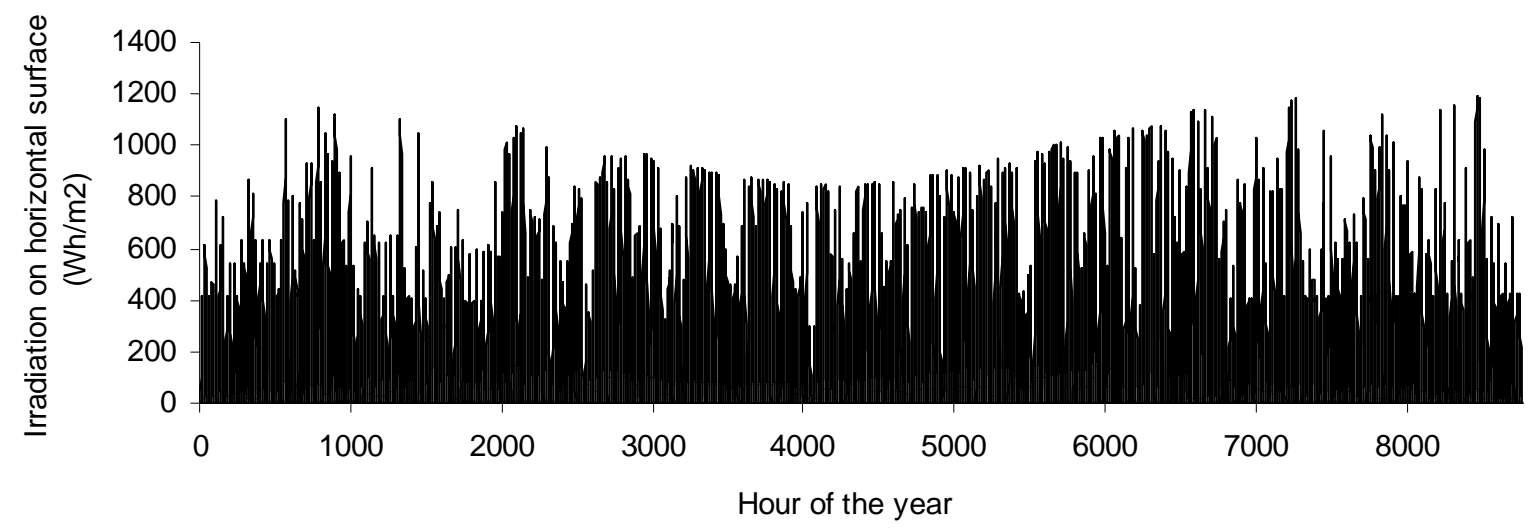

Fig.4. Irradiation on horizontal surface data.

\section{Economical and technical data.}

The system has a 48V DC voltage. The nominal interest rate considered is $7 \%$ annually. This rate is applied to calculate the NPC of the system.

The annual general inflation rate is $5 \%$. This rate is applied to calculate the annual costs of O\&M. However some elements have their own annual inflation rate, different from the general inflation rate.

The system lifespam estimated is 25 years, the same as the lifespam expected for the pv panels and wind turbines.

The components considered in the optimization are explained in the following sections.

\subsection{PV panels.}

In table 1 we show the 3 PV panels considered. The number of panels in serial will be always 4 , as the nominal voltage of the panels is $12 \mathrm{~V}$ and the DC bus voltage is $48 \mathrm{~V}$.

The minimum number of panels in parallel allowed is 0 and the maximum is 50 .

The panels have an scope of $20^{\circ}, 180^{\circ}$ azimuth and 0.2 albedo. The loss factor considered is 1.2 .
The annual O\&M cost is $50 € /$ year for any PV generator (group of $\mathrm{PV}$ panels in serial and parallel) considered.

\begin{tabular}{lccc}
\hline $\begin{array}{l}\text { Peak Power of the } \\
\text { PV panel (Wp) }\end{array}$ & 55 & 110 & 165 \\
\hline $\begin{array}{l}\text { Shortcut current (A) } \\
\text { Acquisition cost (€) }\end{array}$ & 270 & 500 & 750 \\
\hline Acqu & 10,06 \\
\hline
\end{tabular}

Table 1. PV panels considered.

\subsection{Wind Turbines.}

There are 5 possible different wind turbines, shown in table 2 . The power curve of the type 4 is shown in figure 3 . The type of ground rugosity considered is class 2.5 (0.2 m rugosity length). The height of the hub is $10 \mathrm{~m}$ and the nominal voltage is $48 \mathrm{~V} \mathrm{DC}$ for all of the wind turbines considered.

The minimum number of wind turbines in parallel allowed is 0 and the maximum is 10 .

\begin{tabular}{|c|c|c|c|c|c|}
\hline Type & 1 & 2 & 3 & 4 & 5 \\
\hline Maximum output power (W) & 275 & 640 & 1760 & 3500 & 6500 \\
\hline $\begin{array}{l}\text { Wind speed at maximum output } \\
\text { power }(\mathrm{m} / \mathrm{s})\end{array}$ & 14 & 14 & 14 & 14 & 14 \\
\hline Output power $(\mathrm{W})$ at $2 \mathrm{~m} / \mathrm{s}$ & 0 & 0 & 0 & 0 & 0 \\
\hline Output power $(\mathrm{W})$ at $4 \mathrm{~m} / \mathrm{s}$ & 30 & 75 & 240 & 505 & 1000 \\
\hline Output power $(\mathrm{W})$ at $6 \mathrm{~m} / \mathrm{s}$ & 75 & 180 & 600 & 1000 & 2000 \\
\hline Output power $(W)$ at $8 \mathrm{~m} / \mathrm{s}$ & 150 & 350 & 1000 & 1900 & 3700 \\
\hline Output power $(\mathrm{W})$ at $10 \mathrm{~m} / \mathrm{s}$ & 210 & 510 & 1260 & 2500 & 5000 \\
\hline Output power $(\mathrm{W})$ at $12 \mathrm{~m} / \mathrm{s}$ & 250 & 605 & 1500 & 3100 & 6000 \\
\hline Output power (W) at $14 \mathrm{~m} / \mathrm{s}$ & 275 & 640 & 1760 & 3500 & 6500 \\
\hline
\end{tabular}




\begin{tabular}{lccccc}
\hline Output power $(\mathbf{W})$ at $\mathbf{1 6} \mathbf{~ m} / \mathbf{s}$ & 215 & 525 & 1480 & 3000 & 5800 \\
\hline Output power $(\mathbf{W})$ at $\mathbf{1 8} \mathbf{~ m} / \mathbf{s}$ & 220 & 535 & 1540 & 3100 & 6000 \\
\hline Output power $(\mathbf{W})$ at $\mathbf{2 0 ~} \mathbf{~ m} / \mathbf{s}$ & 230 & 550 & 1650 & 3300 & 6000 \\
\hline Output power $(\mathbf{W})$ at $>\mathbf{2 2} \mathbf{~ m} / \mathbf{s}$ & 0 & 0 & 0 & 0 & 0 \\
\hline O\&M cost $(\boldsymbol{\epsilon})$ & 50 & 50 & 50 & 55 & 60 \\
\hline Acquisition cost (€) & 2273 & 3013 & 4114 & 6525 & 10018 \\
\hline
\end{tabular}

Table 2. Wind turbines considered.

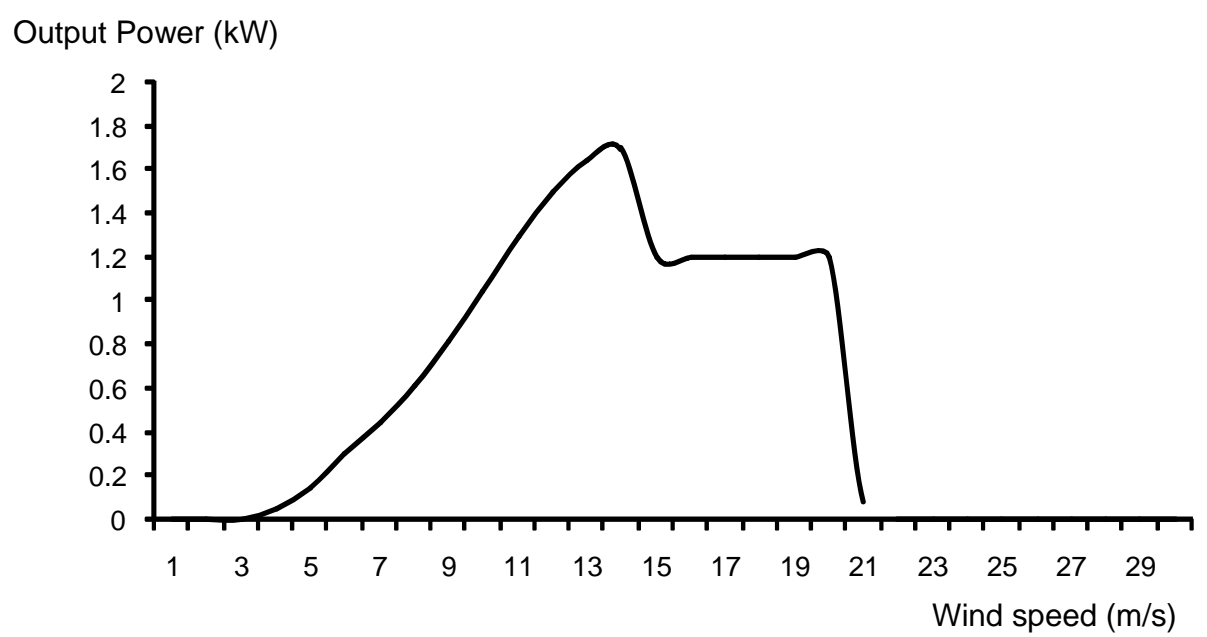

Fig.5. Power curve of wind turbine type 2.

\section{Computacional results.}

Applying the enumerative method for the optimization of the PV-Wind system, the total number of combinations of PV-Wind systems is, in this case:

$N_{\text {types_pv }} \cdot\left(N_{\text {max_pv_parallel }}-N_{\text {min_pv_parallel }}+1\right) \cdot$ $N_{\text {types_wind_t }} \cdot\left(N_{\text {max_wind_t_parallel }}-N_{\text {min_wind_t_parallel }}+\right.$ 1) $=3 \cdot 51 \cdot 5 \cdot 11=8415$

With a Pentium IV $3.4 \mathrm{GHz}, 1$ GB RAM, about 50 evaluations can be performed per second. Evaluating all the combinations has taken 2.7 minutes.

\subsection{Optimal PV-wind system.}

The optimal PV-Wind system found is a WindOnly system, composed by 3 wind turbines of type 4.
The unmet load of the optimal system is $0 \%$. The energy demanded by the pump in the year is $1641 \mathrm{kWh} /$ year. The energy delivered by the wind turbines in the year is $6992 \mathrm{kWh} /$ year. The excess energy (energy which can not be used) is $5351 \mathrm{kWh}$ /year. The NPC of this optimal system is $22596 €$.

In fig. 6, 7 and 8 the energy produced by wind turbines, the energy used by the water pump and the excess energy are shown.

In fig. 9 the energy of water stored in the water tank is shown.

\section{Conclusions.}

In this paper we have shown the application of HOGA to find the optimal PV-Wind system to supply the energy for a DC water pump to feed the water consumption in a small town in Bolivia. The enumerative method has been applied in the optimization process. 


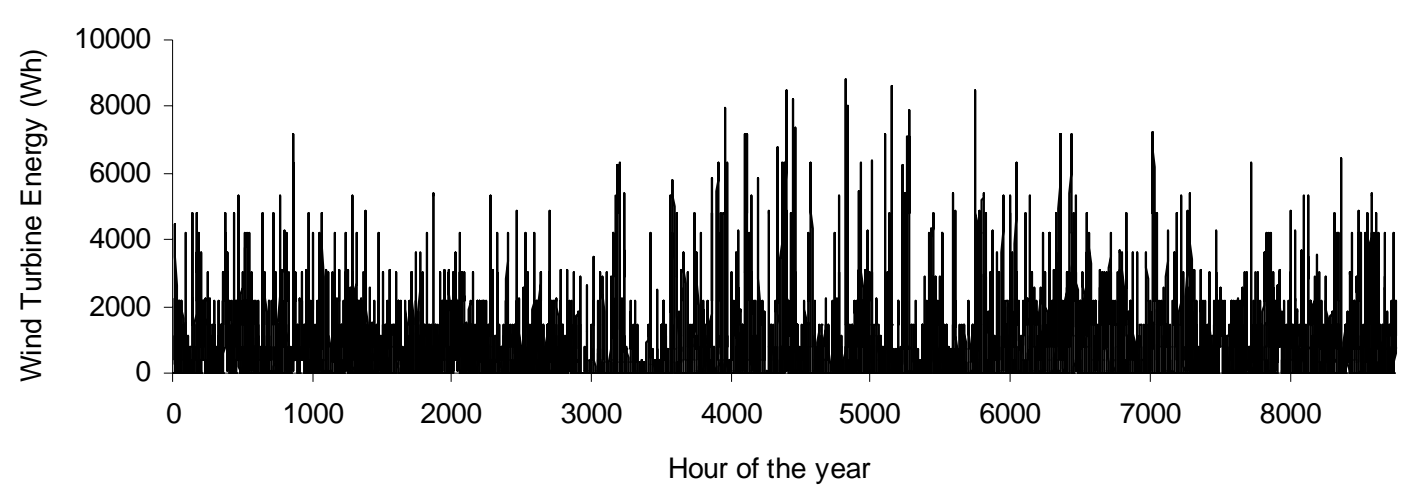

Fig.6. Energy delivered by wind turbines.

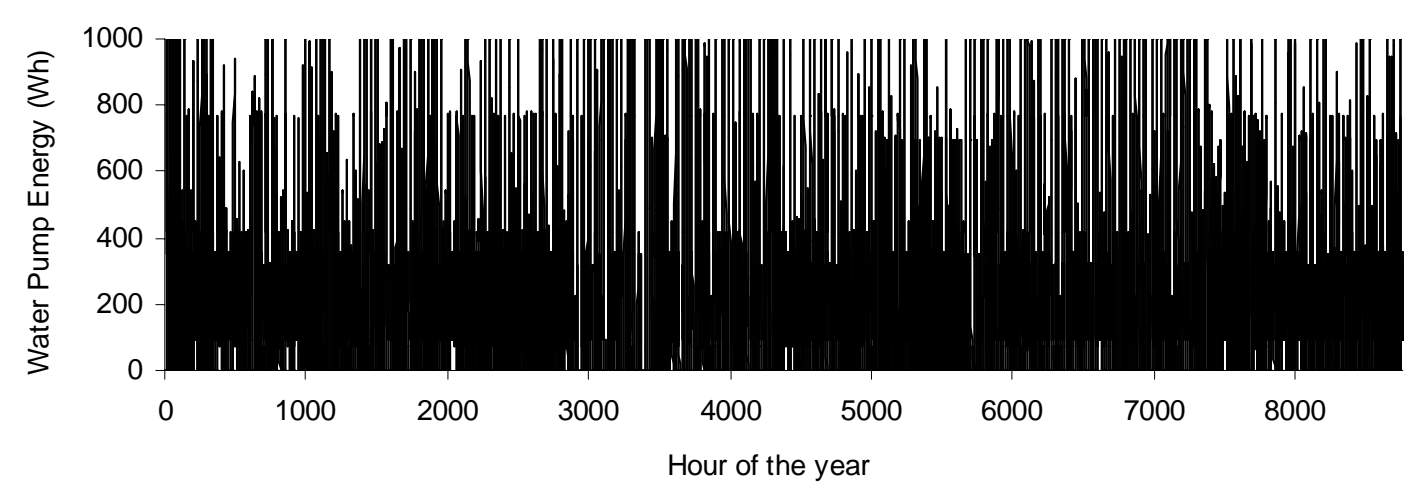

Fig.7. Energy used by water pump.

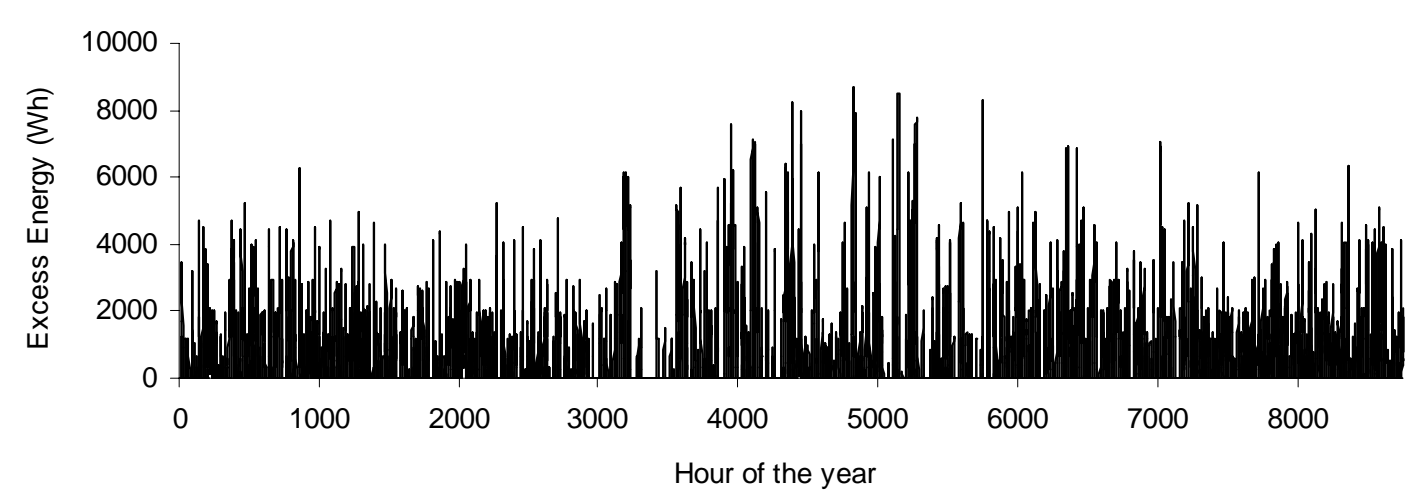

Fig. 8. Excess energy.

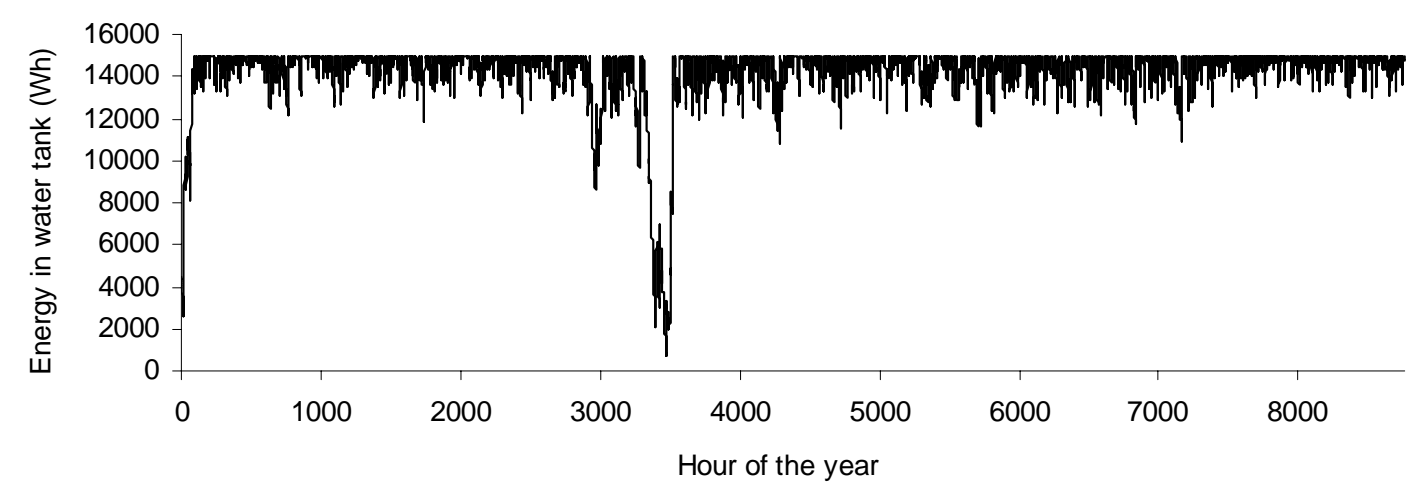

Fig.9. Energy of water stored in the water tank. 


\section{Acknowledgments}

This work was supported by the "Ministerio de Educación y Ciencia” of the Spanish Government under Project ENE200614973/ALT and by the FEDER funds of the European Union.

\section{References.}

[1] Muselli M, Notton G, Louche A. Design of Hybrid-Photovoltaic Power Generator, with Optimization of Energy Management. Solar energy 1999; 65(3):143-57.

[2] Seeling-Hochmuth GC. A Combined Optimisation concept for the Design and Operation Strategy of Hybrid-PV Energy Systems. Solar Energy 1997; 61(2):77-87.

[3] Dufo-López R, Bernal-Agustín JL. Design and control strategies of PV-Diesel systems using genetic algorithms. Solar Energy 2005; 79(1):33-46
[4] Bernal-Agustín JL, Dufo-López R, RivasAscaso, DM. Design of isolated hybrid systems minimizing costs and pollutant emissions. Renewable Energy 2006; 31(14) pp. 2227-2244.

[5] Dufo-López R, Bernal-Agustín JL, Contreras, J. Optimization of Control Strategies for Stand-Alone Renewable Energy Systems with Hydrogen Storage. Renewable Energy 2007; 32 (7) pp. 11021126.

[6] Dufo-López R. 2007. Dimensionado y control óptimos de sistemas híbridos aplicando algoritmos evolutivos (Design and control of hybrid systems using evolutionary algorithms). April 2007. PhD Thesys. Universidad de Zaragoza (University of Saragossa).

[7] Dufo-López, R., Bernal-Agustín, J.L. Influence of the Mathematical Models in the Design of PV-Diesel Systems. Energy Conversion and Management. In press 